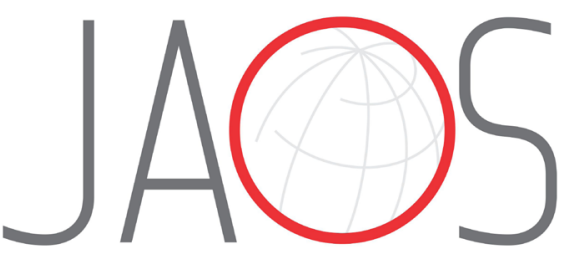
JOURNAL OF APPLIED ORAL SCIENCE

\title{
Physicochemical properties and effect of bioceramic root canal filling for primary teeth on osteoblast biology
}

\section{Abstract}

Victor Manuel OCHOA RODRÍGUEZ1

Mario TANOMARU-FILHO' ${ }^{1}$

Elisandra Márcia RODRIGUES ${ }^{1}$

Eduarda de Oliveira BUGANÇA ${ }^{1}$

Juliane Maria

GUERREIRO-TANOMARU ${ }^{1}$

Gisele FARIA ${ }^{1}$
Submitted: October 10, 2020 Modification: January 30, 2021

Accepted: March 14, 2021
Corresponding address: Gisele Faria

Universidade Estadual Paulista Julio de Mesquita Fillho (UNESP) - Faculdade de Odontologia de Araraquara - Departamento de Odontologia Restauradora - Rua Humaitá, 1680 - 14.801-903 Araraquara - SP - Brasil. 8 - Fax: +55 16 3301-6392 e-mail: gisele.faria@unesp.br
Bio-C Pulpecto (Bio-CP) was recently developed as the first bioceramic root filling material for primary teeth. Objective: To evaluate the physicochemical properties of radiopacity, setting time, $\mathrm{pH}$, cytocompatibility and potential of Bio-CP to induce mineralisation, compared with (1) Calen thickened with zinc oxide (Calen-ZO), and (2) zinc oxide and eugenol (ZOE). Methodology: Physicochemical properties were evaluated according to ISO 6876. Saos-2 (human osteoblast-like cell line) exposed to extracts of the materials were subjected to assays of methyl thiazolyl tetrazolium, neutral red, alkaline phosphatase (ALP) activity and mineralised nodule production. The results were analysed using one-way or two-way ANOVA and Tukey's or Bonferroni's post-tests $(a=0.05)$. Results: All the materials showed radiopacity higher than $3 \mathrm{~mm}$ Al. Bio-CP had lower $\mathrm{pH}$ than Calen-ZO, but higher $\mathrm{pH}$ than ZOE. Calen-ZO and Bio-CP did not set. The setting time for ZOE was 110 min. The cytocompatibility order was Calen-ZO $>$ Bio-CP $>$ ZOE $(1: 2,1: 4$ dilutions) and Calen-ZO $>$ Bio-CP $=\operatorname{ZOE}(1: 12,1: 24$ dilutions $)$ and Calen$Z O=$ Bio-CP $>$ ZOE (1:32 dilution). Bio-CP induced greater ALP activity at 7 days, and greater mineralised nodule production, compared to Calen-ZO $(p<0.05)$. Conclusions Bio-CP showed adequate physicochemical properties, cytocompatibility and potential to induce mineralisation.

Keywords: Cytotoxicity. Endodontics. Primary teeth. Root Canal Filling Materials.
'Universidade Estadual Paulista "Julio de Mesquita Fillho" (UNESP) - Faculdade de Odontologia de Araraquara - Departamento de Odontologia Restauradora - Araraquara - SP - Brasil. 


\section{Introduction}

An ideal root canal filling for primary teeth should not hinder the eruption of permanent successor teeth, but rather, should be resorbed as the deciduous tooth roots are physiologically resorbed, and should also resorb readily if pressed beyond the apex, be easily removed if necessary, be radiopaque and not discolour the tooth. ${ }^{1}$

Zinc oxide and eugenol (ZOE) are a combination that has been used as a root canal filling material in primary dentition for a long time. ${ }^{2,3}$ However, ZOE is genotoxic and cytotoxic, ${ }^{4}$ and cannot be completely phagocytised, leaving particles in periapical tissues when extravasated beyond the apex, and after physiological root resorption of the deciduous teeth. ${ }^{2}$

Calen (S.S. White, Rio de Janeiro, RJ, Brazil) is a commercial calcium hydroxide-based paste with a viscous vehicle (i.e., polyethylene glycol 400), and has suitable biological properties. ${ }^{5}$ Calen thickened with zinc oxide (Calen-ZO) has been used as a root canal filling material in the primary dentition. ${ }^{6-8}$ The addition of zinc oxide ( $Z O)$ reduces the phagocytosis of Calen, thus allowing Calen to accompany the physiological resorption of primary tooth roots, and improve its physicochemical properties. ${ }^{7,9}$ Calen-ZO induces good tissue response, ${ }^{7,10}$ has antimicrobial activity ${ }^{6}$, and is more biocompatible than ZOE. ${ }^{7,8}$

New endodontic cements have been developed, especially highlighting the advance in improved bioceramics. The main characteristics of bioceramic materials for endodontic use are their alkaline $\mathrm{pH}$, shrink-free property, chemical stability within the biological environment, ${ }^{11,12}$ biocompatibility and bioactivity. ${ }^{13,14}$ Bio-C Pulpecto (Bio-CP) (Angelus, Basil, Londrina, Paraná, Brazil) is the first bioceramic root filling material for primary teeth. It is composed of ester glycol salicylate, titanium oxide, calcium tungstate, silicon dioxide, toluene sulphonamide, and calcium silicate (Material Safety Data Sheet information, product in development, file annexed). According to its manufacturer, it presents high alkalinity $(\mathrm{pH} 12.7)$, high radiopacity ( $9 \mathrm{~mm}$ of aluminium scale), complies with ISO $6876,{ }^{15}$ and is resorbable, thus allowing simultaneous physiological resorption of the root and the material (Bio-C Pulpecto, Angelus, Basil, Londrina, Paraná, Brazil). A recent study showed that the Bio-CP is biocompatible and induced biomineralization in the subcutaneous tissue of rats, in a manner similar to MTA. ${ }^{16}$ In addition, a root filling material for primary teeth developed by Angelus, with similar composition of Bio-CP, but with the name not informed, showed good biocompatibility in the subcutaneous tissue of rats, low cytotoxicity in human gingival fibroblast, and satisfactory behaviour regarding the physicochemical properties studied. ${ }^{8}$ However, the scientific literature about Bio-CP is still scarce.

Thus, the aim of this study was to evaluate (1) the physicochemical properties of radiopacity, setting time and $\mathrm{pH}$, and (2) the biological properties of cytocompatibility and potential to induce mineralisation of Bio-CP, compared with Calen-ZO and $\mathrm{ZOE}$, in vitro assays. The null hypothesis was that there would be no difference in the physicochemical and biological properties among the materials.

\section{Methodology}

Root filling materials, manufacturers and proportions for manipulation are shown in Figure 1.

\section{Radiopacity evaluation}

Eight specimens of each material, measuring 10 $\mathrm{mm}$ diameter and $1 \mathrm{~mm}$ high were prepared according to ISO $6876: 2012^{15}$ (Figure 1). The specimens were stored at $37^{\circ} \mathrm{C}$ and $95 \%$ humidity for 3 times the setting time for ZOE, until achieving maximum hardening for Bio-CP and Calen-ZO. Afterwards, they were placed on top of a KODAK CMOS digital sensor (6100, Kodak Co.), next to an aluminium step-wedge ( $98.5 \%$ of $\mathrm{Al}, 8$ steps with $2 \mathrm{~mm}$ increments for each step) for radiographic exposure. Focus 50540 x-ray unit (Instrumentarium Dental; Tuusula, Finland) was

\begin{tabular}{|c|c|c|}
\hline Material & Manufacturer & Proportion for manipulation \\
\hline Bio-C Pulpecto* & Angelus Indústria de Produtos Odontológicos S/A, Londrina, PR, \\
Brazil. & Ready for use \\
\hline Calen+Zinc oxide (Calen-ZO) & $\begin{array}{c}\text { S.S. White Artigos Dentários Ltda., Rio de Janeiro, RJ, Brazil. } \\
\text { Biodinâmica Química e Farmacêutica LTDA, Ibiporã, PR, Brazil. }\end{array}$ & $0.24 \mathrm{~g}$ Calen+0.12g ZO \\
\hline Zinc oxide and eugenol (ZOE) & Biodinâmica Química e Farmacêutica. & $0.54 \mathrm{~g} Z \mathrm{ZO}+100 \mu \mathrm{L}$ of eugenol \\
\hline
\end{tabular}

Figure 1- Root canal filling material, manufacturer and proportion of use. * Product under development, batch no. 190118 
used, and the parameters were set at $65 \mathrm{kVp}, 7 \mathrm{~mA}$, exposure time of 0.16 seconds and a $320 \mathrm{~mm}$ sourceto-object distance. ${ }^{17}$ The digital images obtained were evaluated using methodology developed by OchoaRodriguez, et al. ${ }^{17}$ (2019).

\section{$\mathrm{pH}$ analysis}

Ten polyethylene tubes $10-\mathrm{mm}$ long with $1 \mathrm{~mm}$ internal diameter were filled with each material. Each specimen was immersed in $10 \mathrm{~mL}$ of deionised water, inside of a plastic flask sealed individually with a lid, and then stored at $37^{\circ} \mathrm{C}$. The experimental time intervals were $1,3,7,14$ and 28 days. The $\mathrm{pH}$ of the solution was assessed with a previously calibrated digital pH meter (Digimed; São Paulo, SP, Brazil) at each time interval. The control group consisted of deionised water with no immersed material.

\section{Setting time}

Calen-ZO and ZOE were inserted into ring-shaped metal moulds $1 \mathrm{~mm}$ wide and $10 \mathrm{~mm}$ diameter $(n=6)$, kept at $37^{\circ} \mathrm{C}$ and $95 \%$ humidity. A plaster mould with the same dimensions was prepared for BioCP. The plaster mould was previously submerged in deionised water for 24 hours to provide the bioceramic material with moisture. The setting time was assessed using a Gillmore needle with a mass of $100 \mathrm{~g} \pm 0.5$ and diameter of $2.0 \mathrm{~mm} \pm 0.1$, according to ISO $6876: 2012 .{ }^{15}$ The setting time of the specimens was established as the time elapsing from initial mixing of Calen-ZO and syringe application of Bio-CP up to the maximum hardening of the specimens. At this point, the indentation marks made by the Gillmore needle were substantially reduced, but not eliminated. This is because the pastes had not set. Comparatively, the setting time for ZOE was considered as the time elapsing from when it started to be mixed until such time as the Gillmore needle failed to leave marks on the surface of the specimens.

\section{Cell culture and preparation of root filling materials}

Saos-2 (human osteoblast-like cell) immortalized cells line were grown in flasks containing Dulbecco's Modified Eagle Medium (DMEM; Sigma-Aldrich, St. Louis, MO, USA) supplemented with $10 \%$ fetal bovine serum (FBS, Gibco Life Technologies, Grand Island, $\mathrm{NY}$, USA), penicillin (100 IU / $\mathrm{mL}$ ), and streptomycin $(100 \mu \mathrm{g} / \mathrm{mL})$, in an atmosphere with 5\% CO2 and $95 \%$ humidity at $37^{\circ} \mathrm{C}$.
After handling of the specimens, $100 \mathrm{mg}$ of each material (Figure 1) was placed in a $1.5 \mathrm{~mL}$ microtube (Eppendorf, Hamburg, Germany), to which 1.2 $\mathrm{mL}$ of DMEM was added, followed by placement of the microtubes in an oven at $37^{\circ} \mathrm{C}$ for 24 hours. ${ }^{18}$ Afterwards, the supernatant was transferred to new microtubes centrifuged for $10 \mathrm{~min}$ at $20,800 \mathrm{~g}$ (5430, Eppendorf AG, Hamburg, Germany) to decant any particles of material left in the supernatant. The supernatant was transferred to a new tube and was considered as the "stock solution/extract". It was then diluted and placed in contact with Saos-2 cells. ${ }^{19}$

Cell viability analysis by methyl thiazolyl tetrazolium (MTT) and neutral red (NR) assays

Saos- 2 cells were cultured at a density of $1 \times 10^{5}$ cells/mL in a 96-well plate containing DMEM with $10 \%$ SFB for 24 hours to adhere to the plates. Thereafter, the cells were exposed to the cement extracts at the following dilutions in DMEM ( $v$ : v) $1: 2 ; 1: 4 ; 1: 12$; $1: 24 ; 1: 32$. Cells exposed to DMEM were considered as the control group.

After 24 hours of cell contact with the material extracts and the control, $100 \mu \mathrm{L}$ of $5 \mathrm{mg} / \mathrm{mL}$ MTT solution (Sigma-Aldrich) was added to each well, followed by incubation at $37^{\circ} \mathrm{C}, 95 \%$ humidity and $5 \% \mathrm{CO}_{2}$ for 3 hours. The colorimetric product was solubilised in $100 \mu \mathrm{l}$ of $0.04 \mathrm{~N}$ acidified isopropanol (Sigma-Aldrich). A spectrophotometer (Elx800; BioTek Instruments, Winooski, VT, USA) at $570 \mathrm{~nm}$ was used to measure the optical densities of the solutions. Absorbance readings were normalised to readings of cells exposed to DMEM, and represented the succinate dehydrogenase activity (cellular metabolism).

The NR assay was performed by applying $100 \mu \mathrm{L}$ DMEM containing NR at 50 $\mathrm{gg} / \mathrm{mL}$ (Sigma-Aldrich) after 24 hours of cell contact with the materials and control extracts. The cells were incubated at $37^{\circ} \mathrm{C}$, $95 \%$ humidity and $5 \% \mathrm{CO}_{2}$ for 3 hours, the contents of the wells were removed, and the colorimetric product was solubilised with $100 \mu \mathrm{L}$ of a solution containing $50 \%$ ethanol and $1 \%$ acetic acid (Sigma-Aldrich). A spectrophotometer (Elx800; Bio-Tek Instruments, Winooski, VT, USA) at $570 \mathrm{~nm}$ was used to measure the optical densities of the solutions. Absorbance readings were normalised to readings of cells exposed to DMEM, and represented the ability to incorporate the dye into viable cell lysosomes. 


\section{Alkaline phosphatase (ALP) activity}

Saos-2 ( $5 \times 10^{4}$ cells $/ \mathrm{mL}$ ) were cultivated in 96-well plates and exposed to the control (DMEM) and the extract of the materials at 1:24 dilution. This dilution was selected after observing the results of MTT assays performed after exposure of cells to cement extracts for 1,3 and 7 days (data not shown). The 1:24 dilution was the highest extract concentration without cytotoxic effects. This is an essential consideration, since dead cells do not show ALP activity. ALP activity was evaluated at periods of 1,3 and 7 days, using the commercial kit (Labtest, Lagoa Santa, MG, Brazil). Extracts of the materials were renewed every two days. Cells were washed with $200 \mu \mathrm{L}$ saline phosphate buffer (PBS) after each experimental period, and a $200 \mu \mathrm{L}$ sodium sulphate solution ( $1 \%$ in distilled water, SigmaAldrich) was added to each well. Then the samples were left to stand for 30 minutes at room temperature. Each sample $(5 \mu \mathrm{L})$ in the sodium sulphate solution was transferred to a microtube (Eppendorf) containing a substrate and a buffer enzyme. Absorbance was measured using a spectrophotometer at $590 \mathrm{~nm}$. Data were expressed as normalised ALP activity with total protein content, detected using the Total Protein Kit (Labtest) at the respective experimental periods. MTT assays were performed together with the ALP activity assay to follow up cell viability.

\section{Alizarin Red Staining (ARS)}

Saos- 2 cells were cultivated $\left(1 \times 10^{4}\right.$ cells / $\left.\mathrm{mL}\right)$ in 12-well culture plates with DMEM, supplemented with $50 \mu \mathrm{g} / \mathrm{mL}$ L-ascorbic acid (Sigma-Aldrich) and 10 mM $\beta$ glycerophosphate (Sigma-Aldrich). The cells were exposed to material extracts for 21 days at the same dilution used for the ALP activity assay. Material extracts were renewed every two days. Then the cells were fixed with $4 \%$ paraformaldehyde (Sigma) and stained with $2 \%$ ARS ( $\mathrm{pH} \mathrm{4.1).} \mathrm{The} \mathrm{cells}$ were incubated at room temperature for 20 minutes, and the dye was aspirated. The wells were washed 4 times with $1 \mathrm{~mL}$ of distilled water for 5 minutes. The water was removed and mineralisation was quantified by dissolving the nodules with $1 \mathrm{~mL}$ of a $10 \%$ cetylpyridinium chloride solution (Sigma Aldrich) added to each well, after which the plate was incubated for 15 minutes under stirring at room temperature. Three $100 \mu \mathrm{L}$ aliquots of the suspension from each well were transferred to a 96-well plate and read with a $562 \mathrm{~nm}$ wavelength filter on a spectrometer (Elx800; Bio-Tek Instruments).

\section{Statistical analyses}

The results were shown as mean and standard deviation in at least two independent experiments performed from triplicate to sextuplicate. The results were analysed by one-way analysis of variance (ANOVA) and the Tukey's post-test, or two-way ANOVA and Bonferroni's post-test ( $a=0.05)$, using GraphPad Prism statistical software (GraphPad Software; San Diego, CA, USA).

\section{Results}

\section{Physicochemical properties}

According to Table 1, all the materials showed radiopacity higher than $3 \mathrm{~mm} \mathrm{Al}$, in agreement with ISO 6876:2012. ${ }^{15}$ There was no difference between Bio-CP and Calen-ZO ( $p>0.05)$, and ZOE showed higher radiopacity than the other materials $(p<0.05)$. The ZOE setting time was 110 minutes. Calen-ZO and Bio-CP were considered to "set" (maximum hardening) at 192 hours and 240 hours, respectively. Although Calen-ZO and Bio-CP pastes had alkaline $\mathrm{pH}$, Calen$\mathrm{ZO}$ had a higher $\mathrm{pH}$ than Bio-CP $(\mathrm{p}<0.05)$. ZOE had a neutral $\mathrm{pH}$ (Table 2 ).

\section{Cell viability}

As shown in Figure 2, the cell viability order at lower dilutions (1:2 and 1:4) was Calen-ZO > Bio-CP > ZOE for MTT and Calen-ZO > Bio-CP = ZOE for NR. As for the intermediate dilutions $(1: 12$ and $1: 24)$, the Calen group had the highest cell viability $(p<0.05)$ in the MTT assay, whereas the Bio-CP and ZOE groups had similar

Table 1- Different letters in the lines indicate statistically significant differences among the materials $(P<0.05) *$ The material did not set after the elapsed "setting" time. ** Partial areas of the material set at the evaluated time

\begin{tabular}{cccc}
\hline & Bio-CP & Calen-ZO & ZOE \\
\hline Radiopacity & $3.50(0.15)^{\mathrm{a}}$ & $3.51(0.12)^{\mathrm{a}}$ & $9.25(0.31)^{\mathrm{b}}$ \\
Setting time & $240.7(0.1)^{\mathrm{a}^{*}}$ & $192.0(0.2)^{\mathrm{b}^{* *}}$ & $1.822(0.01)^{\mathrm{c}}$ \\
\hline
\end{tabular}

Different letters in the lines indicate statistically significant differences among the materials $(P<0.05)$.

*The material did not set after the elapsed "setting" time. ${ }^{* *}$ Partial areas of the material set at the evaluated time. 
cell viability $(p>0.05)$. As for the NR assay, there was no difference between the materials and the control ( $p>0.05)$, except Calen-ZO at 1:24 dilution, that had higher cell viability than the other groups $(p<0.05)$. At the highest dilution (1:32), there was no difference between Calen-ZO and Bio-CP ( $p>0.05)$ in the MTT assay, and both groups had higher cell viability than ZOE. In the NR assay, there was no difference among the materials evaluated at $1: 32$ dilution $(p>0.05)$.

Table 2- Different letters in the lines indicate statistically significant differences among materials $(P<0.05)$

\begin{tabular}{|c|c|c|c|c|}
\hline & Bio-CP & Calen-ZO & ZOE & Control \\
\hline 1 day & $10.07(0.22)^{b}$ & $11.32(0.16)^{c}$ & $7.30(0.16)^{d}$ & $7.04(0.08)^{a}$ \\
\hline 3 days & $9.92(0.30)^{b}$ & $10.84(0.22)^{c}$ & $7.18(0.16)^{\mathrm{a}}$ & $6.94(0.07)^{a}$ \\
\hline 7 days & $8.57(0.70)^{b}$ & $10.34(0.38)^{c}$ & $7.03(0.17)^{\mathrm{a}}$ & $6.94(0.08)^{a}$ \\
\hline 14 days & $9.65(0.29)^{b}$ & $10.01(0.68)^{b}$ & $6.87(0.29)^{\mathrm{a}}$ & $6.50(0.25)^{a}$ \\
\hline 21 days & $8.70(0.45)^{b}$ & $9.70(0.63)^{c}$ & $6.99(0.15)^{\mathrm{a}}$ & $6.64(0.16)^{a}$ \\
\hline 28 days & $8.08(0.73)^{b}$ & $9.65(0.73)^{c}$ & $6.52(0.07)^{d}$ & $5.79(0.14)^{a}$ \\
\hline
\end{tabular}

Different letters in the lines indicate statistically significant differences among the materials $(P<0.05)$.

a)

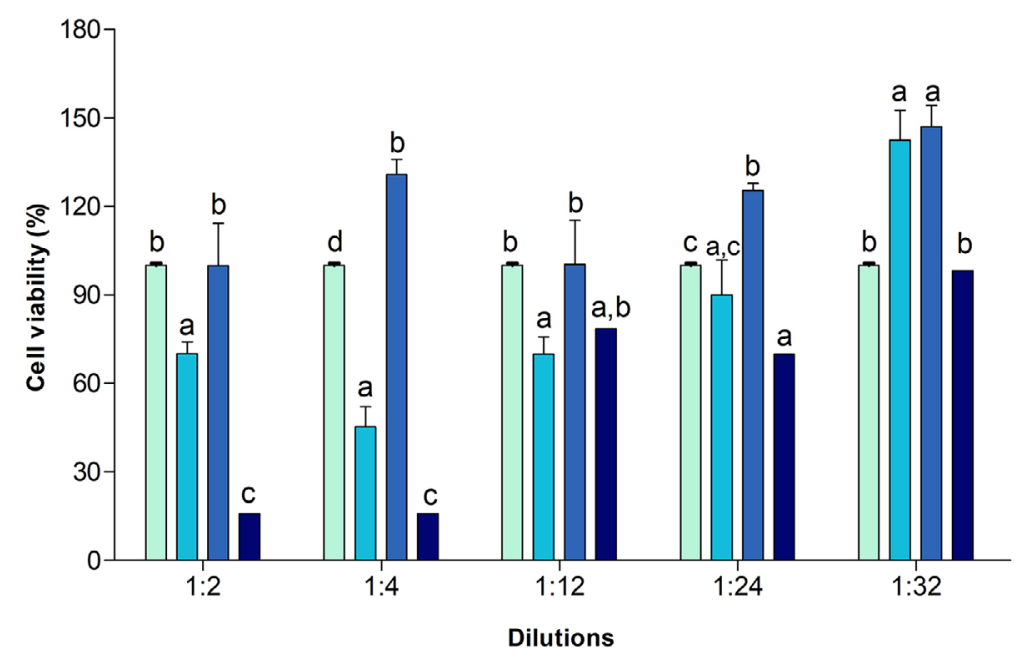

b)

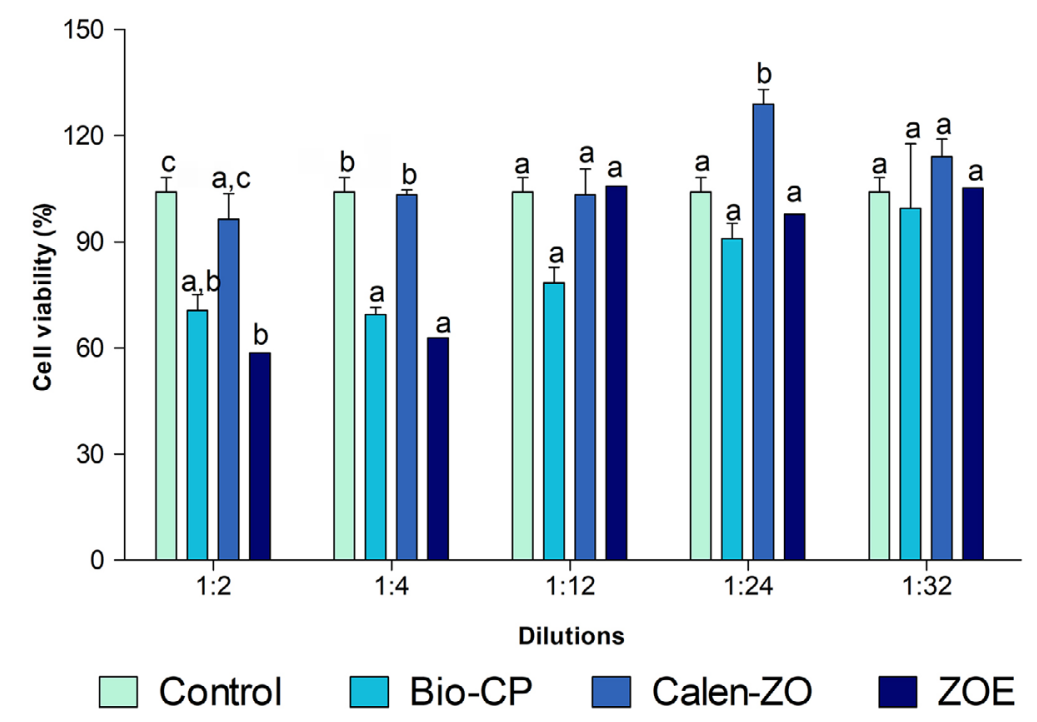

Figure 2- Saos-2 viability evaluated by (a) methyl-thiazol-tetrazolium (MTT) and (b) neutral red (NR) assays, after 24 hours of exposure to Bio-CP, Calen-ZO, ZOE and control (culture medium). Bio-CP=Bio C Pulpecto; Calen-ZO=Calen mixed with zinc oxide; ZOE=Zinc oxide and eugenol. Different letters in each dilution indicate statistically significant differences among the materials $(p<0.05)$ 
a)

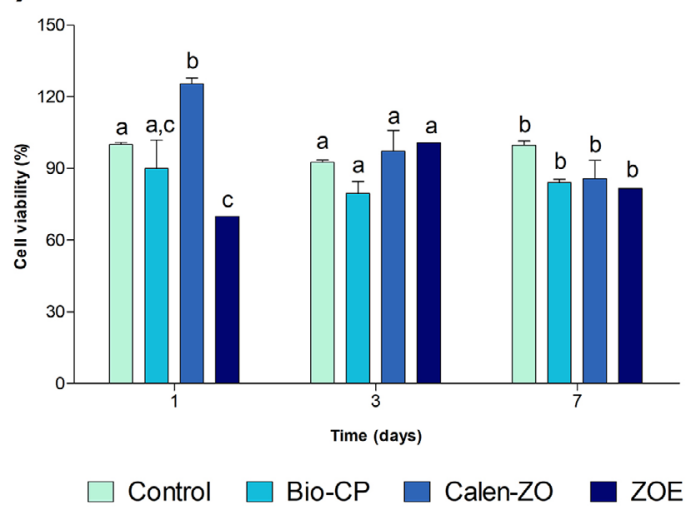

b)

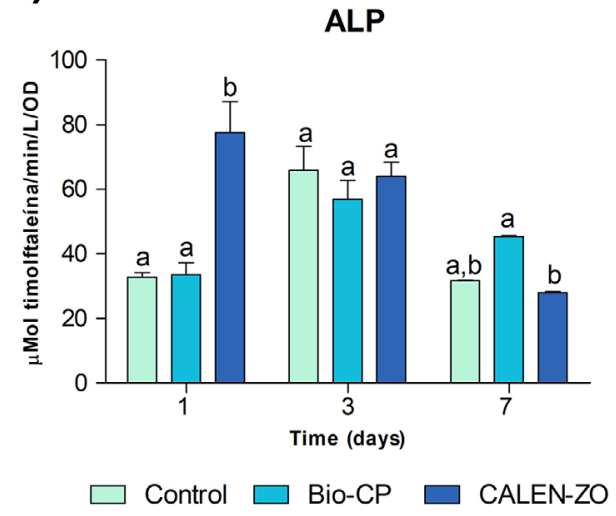

c)

ARS

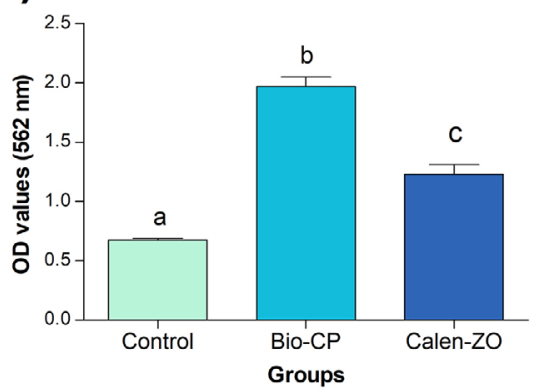

Figure 3- Effect of root canal filling materials (1:24 dilution) of primary teeth on the biology of Saos-2. MTT assay (a) and alkaline phosphatase (ALP) activity (b) were performed 1, 3 and 7 days after exposure of Soas-2 to extracts of materials and serum-free culture medium (control), whereas alizarin red stain (ARS ) assay (c) was evaluated after 21 days of cell exposure to material extracts and osteogenic culture medium (control). Bio- $\mathrm{CP}=\mathrm{Bio} \mathrm{C}$ Pulpecto; Calen-ZO=Calen mixed with zinc oxide and eugenol; $\mathrm{ZOE}=\mathrm{Zinc}$ oxide and eugenol. Different letters indicate statistically significant differences among the materials $(p<0.05)$

\section{Potential to induce mineralisation}

As shown in Figure 3, on the first and third day of Saos-2 exposure to the materials, all groups had similar $(p>0.05)$ or greater cell viability than the control group $(p<0.05)$, except for $Z O E$, which promoted lower cell viability than the control group $(p<0.05)$. On the seventh day, there was no difference in the viability of the cells exposed to all the materials and the control $(p>0.05)$. On the first day of cell culture, Calen-ZO induced higher ALP activity than Bio-CP and the control $(p<0.05)$, whereas Bio-CP promoted ALP activity similar to that of the control ( $p>0.05$ ). On the third day, there was no difference among the groups ( $p>0.05)$. On the seventh day, Bio-CP induced higher ALP activity than Calen-ZO ( $p<0.05)$, whereas Calen-ZO was no different from the control ( $p>0.05)$. In 21 days of cell exposure to the materials, Bio-CP and Calen-ZO induced higher mineralised nodule production than the control $(p<0.05)$, although that of Bio-CP was higher than that of Calen-ZO $(p<0.05)$.

\section{Discussion}

In the present study, a comparison was made of the biological and physicochemical properties of BioCP, Calen-ZO and ZOE. Bio-CP exhibited adequate physicochemical properties, had cytocompatibility and revealed potential to induce mineralisation, when compared to the other evaluated root canal filling materials for primary teeth.

Radiopacity is an essential property for endodontic materials, because it allows endodontic filling material to be viewed by radiographic examination to evaluate the obturation quality, ${ }^{12}$ and make a clear distinction among the materials and the surrounding anatomical structures. ${ }^{20}$ ISO $6876: 2012^{15}$ establishes that the root canal sealers must have at least $3 \mathrm{~mm}$ Al. In the present study, all the materials evaluated showed higher radiopacity than $3 \mathrm{~mm} \mathrm{Al}$. However, the radiopacity value of Bio-CP $(3.50 \mathrm{~mm} \mathrm{Al})$ was less than that stated by the manufacturer ( $9 \mathrm{~mm} \mathrm{AL})$. On the other hand, it agrees with a previous study that showed that an experimental MTA-based material, with 
similar composition of Bio-CP, had radiopacity of $3.28 .^{8}$ The greater radiopacity of ZOE $(9.25 \mathrm{~mm} \mathrm{Al})$ than that of the other materials $(3.5 \mathrm{~mm} \mathrm{Al})$ is attributed to its zinc oxide used as a radiopacifier. ${ }^{21}$

An alkaline medium not only neutralises lactic acid from osteoclasts, but also prevents the mineral components of dentine from dissolving. In addition, it promotes antimicrobial activity, and may activate alkaline phosphatases, which play an important role in hard-tissue formation. ${ }^{22}$ Both Bio-CP and Calen-ZO had alkaline $\mathrm{pH}$; however, Calen-ZO had a higher alkaline $\mathrm{pH}$ compared with Bio-CP over the evaluated periods. Calcium hydroxide dissociates into calcium and hydroxyl ions, which raises the $\mathrm{pH}$ of the medium. Bioceramic materials form calcium hydroxide when they undergo a hydration reaction. ${ }^{12}$ The lower $\mathrm{pH}$ of Bio-C compared to Calen-ZO is probably due to the lower amount of calcium hydroxide released into the medium by Bio-CP.

ZOE had a setting time of 110 minutes. The hardening time of Calen-ZO was 192 hours and that of Bio-CP was 240 hours; neither material set. The fact that Bio-CP does not set is not a disadvantage, since this phenomenon is observed in materials considered suitable for filling root canals of primary teeth. ${ }^{8,9,23}$ Because Bio-CP was developed as a root filling material for primary teeth, is desirable that the material can be reabsorbed to accompany the physiological resorption of deciduous teeth roots. It can be hypothesized that the absence of set, along with the composition and solubility of the material, can allow simultaneous physiological resorption of the root and the material.

Saos- 2 cells were used because they provide a suitable model to evaluate cytocompatibility and the potential to induce mineralisation of the materials. ${ }^{17}$ MTT and NR assays were used to assess the cytocompatibility of the materials. MTT is based on the ability of viable cells to metabolise the MTT salt. NR assesses the ability of viable cells to incorporate dye into lysosomes. ${ }^{17}$ Studies that evaluate different cell parameters make the cytocompatibility results more reliable ${ }^{24}$ ALP activity and mineral nodule production assays were performed to evaluate the potential of materials to induce mineralisation. ALP activity assay is a biomarker of the enzyme alkaline phosphatase produced by osteoblasts in their early maturation process, ${ }^{25}$ and ARS identifies calcium deposits in cell culture. ${ }^{17}$

The cytocompatibility and the potential to induce mineralisation of bioceramic endodontic materials for permanent teeth has been studied in different cell types. EndoSequence BC sealer (Brasseler USA, Savannah, GA, USA) showed low cytotoxicity in L929 fibroblasts, ${ }^{26}$ human gingival fibroblasts ${ }^{27}$ and murine osteoblast precursor cells (IDG- SW3). ${ }^{13}$ Moreover this material promoted osteoblastic differentiation, ${ }^{13}$ showed anti-inflammatory effects and induced mineralisation in osteoblast precursor cells (MC3T3-E1). ${ }^{14}$ Another study comparing mineral trioxide aggregate - MTA (ProRoot; Dentsply Tulsa Dental, Tulsa, OK, USA) and iRoot SP (Innovative BioCreamix, Vancouver, Canada) showed that neither material was cytotoxic in human tooth stem cells. ${ }^{28}$

Bio-CP cytocompatibility was lower compared to Calen-ZO, but higher compared to ZOE. Pilownic, et al. ${ }^{8}$ (2017) showed no statistical difference in the cytotoxicity of Calen-ZO and the experimental MTAbased material with a similar composition of Bio-CP. This difference in result can be explained by the type of cells and also by the Calen-ZO proportion used. While in the present study Saos- 2 cells (osteoblast-like cells), and Calen-ZO in a 2: 1 proportion were used, Pilownic, et al. ${ }^{8}$ (2017) used human gingival fibroblasts and Calen-ZO in a 1: 1 proportion. It is important to emphasize that it is not clear if the manufacturer modified the concentrations of the components in Bio- $\mathrm{CP}$, because at the time of the Pilownic, et al. ${ }^{8}$ (2017) study, the material did not have a name yet and, unfortunately, the manufacturer did not disclose the concentrations.

Bio-CP induced lower ALP activity in 1 day, but greater ALP activity in 7 days, than Calen-ZO. In addition, Bio-CP induced greater mineralised nodule production than Calen-ZO. Calen-ZO induced higher calcium deposits than the control group. A recent study showed that Bio-CP was biocompatible and induced biomineralization similar to MTA in the subcutaneous tissue of rats. ${ }^{16}$ Regarding Calen-ZO, the results of the present study are in line with previous studies performed on dogs' teeth and the subcutaneous tissue of mice, which showed that Calen-Zo was more biocompatible than ZOE. ${ }^{7,10}$ ZOE was not evaluated in either mineralisation assay conducted in the present study, because it has no bioactivity. ${ }^{29}$ The high mineralisation potential of calcium-silicate-based bioceramic materials is attributed to their hydration, that is, a chemical reaction with tissue fluids yields hydrated silicate gel (C-S-H) and calcium hydroxide. ${ }^{30}$ 
These compounds ( $\mathrm{C}-\mathrm{S}-\mathrm{H}$ and calcium hydroxide) each have a mineralisation pathway. Calcium hydroxide induces the formation of calcite crystals that induce the formation of calcified areas. Calcite crystals are formed from the dissociation of calcium ions from calcium hydroxide, and carbon dioxide ions from tissues. ${ }^{31}$ On the other hand, $\mathrm{C}-\mathrm{S}-\mathrm{H}$ induces hydroxyapatite deposition; this reaction is promoted by the hydration of tissue fluids. In bioceramic materials, calcium hydroxide reacts with the phosphate ions in tissue fluids to deposit calcium phosphate. ${ }^{4,30}$

The results obtained for cytocompatibility and mineralization induction should be confirmed by further in vivo studies. In addition, to complement the research on Bio-CP, studies should be carried out to evaluate its antibiofilm activity and the capacity to be reabsorbed to accompany the physiological resorption of deciduous teeth roots.

It was concluded that Bio-CP did not set, presented adequate radiopacity and alkaline $\mathrm{pH}$, was cytocompatible and had the potential to induce mineralisation. Considering its good physicochemical and biological properties, Bio-CP has the potential to become an adequate material for the root canal filling of primary teeth.

\section{Acknowledgements}

This study was funded by fellowships from Fundação de Amparo à Pesquisa do Estado de São Paulo (FAPESP) - Grant no. 19/19766-0, and by Coordenação de Aperfeiçoamento de Pessoal de Nível Superior - Brasil (CAPES) - Funding Code 001.

\section{Conflicts of interest}

There are no conflicts of interest.

\section{Authors' contributions}

Ochoa-Rodriguez, Victor: Data curation (Equal); Formal analysis (Equal); Investigation (Equal); Methodology (Equal); Project administration (Equal); Validation (Equal); Visualization (Equal); Writingoriginal draft (Equal); Writing-review \& editing (Equal).

Tanomaru-Filho, Mário: Conceptualization (Equal); Formal analysis (Equal); Resources (Equal); Writingreview \& editing (Equal). Rodrigues, Elisandra Márcia: Methodology (Equal). Bugança, Eduarda Oliveira: Methodology (Equal); Writing-original draft (Equal). Guerreiro-Tanomaru, Juliane Maria: Formal analysis (Equal); Methodology (Supporting); Resources (Supporting); Visualization (Supporting).
Faria, Gisele: Conceptualization (Lead); Data curation (Lead); Formal analysis (Lead); Funding acquisition (Lead); Investigation (Lead); Methodology (Lead); Project administration (Equal); Resources (Lead); Software (Lead); Supervision (Lead); Validation (Lead); Visualization (Lead); Writing-original draft (Lead); Writing-review \& editing (Lead).

\section{References}

1- Gupta S, Das G. Clinical and radiographic evaluation of zinc oxide eugenol and metapex in root canal treatment of primary teeth. J Indian Soc Pedod Prev Dent. 2011;29(3):222-8. doi: 10.4103/09704388.85829

2- Primosch RE, Ahmadi A, Setzer B, Guelmann M. A retrospective assessment of zinc oxide-eugenol pulpectomies in vital maxillary primary incisors successfully restored with composite resin crowns. Pediatr Dent. 2005;27(6):470-7.

3- Pulp therapy for primary and immature permanent teeth. Pediatr Dent. 2017;15;39(6):325-33

4- Nair AV, Nayak M, Prasada LK, Shetty V, Kumar CN, Nair RR. Comparative evaluation of cytotoxicity and genotoxicity of two bioceramic sealers on fibroblast cell line: an in vitro study. J Contemp Dent Pract. 2018;19(6):656-61

5- Nelson P Filho, Silva LA, Leonardo MR, Utrilla LS, Figueiredo F. Connective tissue responses to calcium hydroxide-based root canal medicaments. Int Endod J. 1999;32(4):303-11. doi: 10.1046/j.13652591.1999.00225.x

6- Queiroz AM, Nelson-Filho P, Silva LA, Assed S, Silva RA, Ito IY Antibacterial activity of root canal filling materials for primary teeth: zinc oxide and eugenol cement, Calen paste thickened with zinc oxide, Sealapex and EndoREZ. Braz Dent J. 2009;20(4):290-6. doi: 10.1590/ s0103-64402009000400005.

7- Silva LA, Leonardo MR, Oliveira DS, Silva RA, Queiroz AM, Hernández $P G$, et al. Histopathological evaluation of root canal filling materials for primary teeth. Braz Dent J. 2010;21(1):38-45. doi: 10.1590/s010364402010000100006

8- Pilownic KJ, Gomes AP, Wang ZJ, Almeida LH, Romano AR, Shen Y, et al. Physicochemical and biological evaluation of endodontic filling materials for primary teeth. Braz Dent J. 2017;28(5):578-86. doi: 10.1590/0103-644020170157

9- Segato RA, Pucinelli CM, Ferreira DC, Daldegan AR, Silva RS, Nelson-Filho $P$, et al. Physicochemical properties of root canal filling materials for primary teeth. Braz Dent J. 2016;27(2):196-201. doi: 10.1590/0103-6440201600206

10- Queiroz AM, Assed S, Consolaro A, Nelson-Filho P, Leonardo MR, Silva RA, et al. Subcutaneous connective tissue response to primary root canal filling materials. Braz Dent J. 2011;22(3):203-11. doi: 10.1590/s0103-64402011000300005

11- Loushine BA, Bryan TE, Looney SW, Gillen BM, Loushine RJ, Weller RN, et al. Setting properties and cytotoxicity evaluation of a premixed bioceramic root canal sealer. J Endod. 2011;37(5):673-7. doi: 10.1016/j.joen.2011.01.003

12- Candeiro GT, Correia FC, Duarte MA, Ribeiro-Siqueira DC, Gavini $\mathrm{G}$. Evaluation of radiopacity, $\mathrm{pH}$, release of calcium ions, and flow of a bioceramic root canal sealer. J Endod. 2012;38(6):842-5. doi: 10.1016/j.joen.2012.02.029

13- Giacomino CM, Wealleans JA, Kuhn N, Diogenes A. Comparative biocompatibility and osteogenic potential of two bioceramic sealers. J Endod. 2019;45(1):51-6. doi: 10.1016/j.joen.2018.08.007 
14- Lee BN, Hong JU, Kim SM, Jang JH, Chang HS, Hwang YC, et al. Antiinflammatory and osteogenic effects of calcium silicate-based root canal sealers. J Endod. 2019;45(1):73-78. doi: 10.1016/j.joen.2018.09.006 15- International Organization for Standardization. ISO 6876:2012 Dentistry: root canal sealing materials. Geneva: ISO; 2012.

16- Cosme-Silva L, Benetti F, Dal-Fabbro R, Gomes JE Filho, Sakai VT, Cintra LT, et al. Biocompatibility and biomineralization ability of Bio-C Pulpecto. A histological and immunohistochemical study. Int J Paediatr Dent. 2019;29(3):352-60. doi: 10.1111/ipd.12464

17- Ochoa-Rodríguez VM, Tanomaru-Filho M, Rodrigues EM, GuerreiroTanomaru JM, Spin-Neto R, Faria G. Addition of zirconium oxide to Biodentine increases radiopacity and does not alter its physicochemical and biological properties. J Appl Oral Sci. 2019;27:e20180429. doi: 10.1590/1678-7757-2018-0429

18- Pires CW, Botton G, Cadoná FC, Machado AK, Azzolin VF, Cruz IB, et al. Induction of cytotoxicity, oxidative stress and genotoxicity by root filling pastes used in primary teeth. Int Endod J. 2016;49(8):737-45. doi: $10.1111 /$ iej.12502

19- Faria G, Rodrigues EM, Coaguila-Llerena $H$, Gomes-Cornélio AL, Neto Angéloco RR, Swerts Pereira MS, et al. Influence of the vehicle and antibiotic formulation on cytotoxicity of triple antibiotic paste. J Endod. 2018;44(12):1812-6. doi: 10.1016/j.joen.2018.09.009 20- American National Standards Institute /American Dental Association (ANSI/ADA) Specification $n^{\circ} 57$. Laboratory testing methods: endodontic filling and sealing materials. Chicago: ADA; 2008. 21- Camilleri J, Gandolfi MG. Evaluation of the radiopacity of calcium silicate cements containing different radiopacifiers. Int Endod J. 2010;43(1):21-30. doi: 10.1111/j.1365-2591.2009.01621.x

22- Muramatsu T, Kashiwagi S, Ishizuka $H$, Matsuura $Y$, Furusawa $M$, Kimura $M$, et al. Alkaline extracellular conditions promote the proliferation and mineralization of a human cementoblast cell line. Int Endod J. 2019;52(5):639-45. doi: 10.1111/iej.13044
23- Sari S, Okte Z. Success rate of Sealapex in root canal treatment for primary teeth: 3-year follow-up. Oral Surg Oral Med Oral Pathol Oral Radiol Endod. 2008;105(4):e93-6. doi: 10.1016/j.tripleo.2007.12.014 24- Peters OA. Research that matters - biocompatibility and cytotoxicity screening. Int Endod J. 2013;46(3):195-7. doi: 10.1111/iej.12047 25- Bellows CG, Aubin JE, Heersche JN. Initiation and progression of mineralization of bone nodules formed in vitro: the role of alkaline phosphatase and organic phosphate. Bone Miner. 1991;14(1):27-40. doi: 10.1016/0169-6009(91)90100-e

26- Zoufan K, Jiang J, Komabayashi T, Wang YH, Safavi KE, Zhu Q. Cytotoxicity evaluation of Gutta Flow and Endo Sequence BC sealers. Oral Surg Oral Med Oral Pathol Oral Radiol Endod. 2011;112(5):65761. doi: 10.1016/j.tripleo.2011.03.05

27- Zhou HM, Du TF, Shen Y, Wang ZJ, Zheng YF, Haapasalo M. In vitro cytotoxicity of calcium silicate-containing endodontic sealers. J Endod. 2015;41(1):56-61. doi: 10.1016/j.joen.2014.09.012

28- Güven EP, Taşlı PN, Yalvac ME, Sofiev N, Kayahan MB, Sahin F. In vitro comparison of induction capacity and biomineralization ability of mineral trioxide aggregate and a bioceramic root canal sealer. Int Endod J. 2013 Dec;46(12):1173-82. doi: 10.1111/iej.12115

29- Bernabé PF, Holland R, Morandi R, Souza V, Nery MJ, Otoboni Filho JA, et al. Comparative study of MTA and other materials in retrofilling of pulpless dogs' teeth. Braz Dent J. 2005;16(2):149-55. doi: 10.1590/ s0103-64402005000200012

30- Camilleri J. Characterization and hydration kinetics of tricalcium silicate cement for use as a dental biomaterial. Dent Mater. 2011;27(8):836-44. doi: 10.1016/j.dental.2011.04.010

31- Bueno CR, Valentim D, Marques VA, Gomes-Filho JE, Cintra LT, Jacinto RC, et al. Biocompatibility and biomineralization assessment of bioceramic-, epoxy-, and calcium hydroxide-based sealers. Braz Oral Res. 2016;30(1):S1806-83242016000100267. doi: 10.1590/18073107BOR-2016.vol30.0081 